\title{
Live Synchronous Web Meetings in Asynchronous Online Courses: Reconceptualizing Virtual Office Hours
}

\author{
Patrick R. Lowenthal and Chareen Snelson \\ Boise State University \\ Joanna C. Dunlap \\ University of Colorado, Denver
}

\begin{abstract}
Most online courses rely solely on asynchronous text-based online communication. This type of communication can foster anytime, anywhere reflection, critical thinking, and deep learning. However, it can also frustrate participants because of the lack of spontaneity and visual cues and the time it takes for conversations to develop and feedback to be shared, as well as the selfdirectedness and discipline it requires of participants to regularly check in and monitor discussions over time. Synchronous forms of online communication can address some of these constraints. However, online educators often avoid using synchronous forms of communication in their courses, because of its own constraints. In this paper, we describe how we integrated live synchronous web meetings into asynchronous online courses, collected student feedback, and made iterative changes and refinements based on student feedback over time. We conclude with implications for practice.
\end{abstract}

Keywords: Synchronous communication, asynchronous communication, live meetings, Web conferencing, office hours, social presence, instructional design

Lowenthal, P. R.; Dunlap, J. C. \& Snelson, C. (2017). Live synchronous web meetings in asynchronous online courses: Reconceptualizing virtual office hours. Online Learning 21(4), 177-194. doi: 10.24059/olj.v21i4.1285

\section{Live Synchronous Web Meetings in Asynchronous Online Courses: Reconceptualizing Virtual Office Hours}

Online learning comes in many forms (Lowenthal, Wilson, \& Parrish 2009; Moore, Dickson-Deane, \& Galyen, 2011). The most popular is the type offered in schools and universities that relies predominantly, if not solely, on asynchronous text-based communication (Bowman, 2010; Johnson, 2006; Shea \& Bidjerano, 2009). Asynchronous text-based communication 
technology enables students to work at their own pace within a designated timeframe (e.g., one week) as they meet course deadlines (Huang \& Hsiao, 2012; Murphy, Rodríguez-Manzanares, Barbour, 2011). Despite the widespread use of this type of communication in online courses, there are challenges with relying only on asynchronous text-based communication (Dunlap, Bose, Lowenthal, York, Atkinson, \& Murtagh, 2016; Fadde \& Vu, 2014). Perhaps one of the most notable challenges is the lack of visual cues and the time it takes for conversations to develop with asynchronous text-based communication (Fadde \& Vu, 2014; Huang \& Hsiao, 2012). Live synchronous video-based communication - whether one-on-one (e.g., Skype and FaceTime) or many-to-many (e.g., Adobe Connect, Zoom, and Google Hangouts) - can address many of the challenges of asynchronous text-based communication. For instance, synchronous video-based communication happens in real time and therefore can be more expedient and help establish others as being "real" and "there" (Fadde \& Vu, 2014; Martin \& Parker, 2014; Martin, Parker, \& Deale, 2012). However, despite the benefits of synchronous video-based communication, many faculty avoid using this form of communication in online courses (see Huang \& Hsiao, 2012; Martin \& Parker, 2014; Palloff \& Pratt, 2007). Some of the commonly cited reasons faculty avoid using synchronous video-based communication include (a) the belief that students enroll in online courses to avoid having to be in class at a specific time, (b) fear of technological and bandwidth issues, (c) scheduling / time zone issues, and (d) the belief that it encourages teacher-centered practices (Anderson, 2003; Huang \& Hsiao, 2012; Palloff \& Pratt, 2007). While each of these reasons are legitimate concerns, we questioned whether the benefits of synchronous video-based communication could outweigh the possible drawbacks. While there is some literature on how to use synchronous text-based communication (e.g., chatting or instant messaging) in online courses, there is surprisingly very little literature on how to use synchronous video-based communication (i.e., web conferencing) in online courses - and almost none on how to use it specifically for virtual office hours (Hrastinski, Keller, \& Carlsson, 2010). Given this gap in the literature, we decided to investigate effective ways to integrate live synchronous video-based communication (i.e., web conferencing) into predominantly asynchronous online courses. In the following paper, we describe how we used live, synchronous, video-based communication for virtual office hours in asynchronous online courses, collected student feedback, and made iterative changes and refinements based on student feedback over time. We conclude with implications for practice.

\section{Background}

This study took place in a fully online graduate program in educational technology at a metropolitan research university. Students in this program live across the United States; a small percentage even live outside of the United States. The instructor (the first author) taught each of the courses involved in this study. Over the past 13 years, the instructor had experimented with different ways to hold office hours with his online students. For instance, as web conferencing technology improved during the mid-2000s, the instructor began hosting "live" (i.e., in real-time) synchronous virtual office hours each week (in Adobe Connect) in asynchronous online courses.

While he was aware of general recommendations found in the literature about holding live virtual office hours (cf. Boettcher \& Conrad, 2016; Finkelstein, 2006; Ko \& Rossen, 2017), there were three main reasons at that time motivating the instructor's use of live virtual office hours. First, he was teaching a multimedia/coding course and he wanted to have a set time that students could come get help in real time. He believed, like others, that the desktop-sharing feature in particular, available in many virtual classrooms/web conference tools, could help him answer student questions and provide just-in-time direct instruction in an efficient and timely manner (cf. 
Martin \& Parker, 2014). Second, he was aware of research suggesting that students often feel isolated and alone in online courses (Bolliger \& Inan, 2012; Ludwig-Hardman \& Dunlap, 2003) and the importance of frequent student-teacher interaction to enhance students' motivation to engage, learn, and persist in online courses (Bernard, Abrami, Borokhovski, Wade, Tamim, Surkes, \& Bethel, 2009; Chickering \& Gamson, 1987). He was also specifically interested in ways to increase instructor social presence using video (Borup, West, \& Graham, 2012; Richardson \& Lowenthal, 2017). Third, as an adjunct instructor with a full-time day job, he was concerned about the amount of time he spent teaching online each week. He hoped that using live, video-based office hours would increase his efficiency and lower his workload by decreasing the volume of asynchronous back-and-forth exchanges with multiple students via discussion forums, email, and text messaging (cf. Dunlap, 2005).

Despite the purported benefits, for years the instructor had mixed success with live, videobased, virtual office hours. He scheduled virtual office hours every Saturday at 10am during the semester. But he repeatedly found that only about $10 \%$ of students would attend the first virtual office hour and after that the number would decrease each week until the point where one lone student (or sometimes no students) would show up. He questioned whether logging in each week for live virtual hours was a good use of his time. After a couple of years, he stopped using live virtual office hours and instead simply held office hours as needed by appointment only-a practice he found adopted by many of his colleagues having similar no-show challenges with virtual office hours.

A few years later, though, he found himself teaching at a new institution and revisiting the utility of video-based, live virtual office hours. He knew that while only a few students showed up in the past, live virtual office hours were still important and valuable to those who did show up. Further, his background in instructional design and computer-mediated communication reminded him that it is not the technology that matters but rather how technology is effectively used in online courses that makes the difference. So, with two colleagues who were also dissatisfied with their use of virtual office hours, he decided to explore ways to best engage students in synchronous video-based interactions via virtual office hours.

\section{Methods}

Technology-based instructional interventions often fail when educators or developers expect technology alone to fix educational problems. Research has consistently shown that technology is not a panacea (Cuban, 2009; Oppenheimer, 1997); pedagogy, and specifically how instruction is designed and implemented, is what makes a difference in student outcomes (Clark, 1983, 1994). Further, the instructional strategies educators and designers plan to use, do not always work as expected when implemented in a classroom with students. Given this, over the years, a growing body of educational researchers have argued that there is a need for more developmental or design-based research (Amiel \& Reeves, 2008; Anderson \& Shattuck, 2012; Brown, 1992; Collins, 1992).

While there are different approaches, design-based research usually involves a team of researchers using educational theory to develop an instructional intervention; the instructional intervention is then implemented in an authentic setting and studied for how well it works. The researchers then make changes to the instructional intervention based on what they learn from their design experiment; they then continue to test the instructional intervention in authentic settings, 
conduct additional design experiments, and make iterative improvements to the intervention over time. Design-based research, therefore, focuses on connecting research, theory, and practice by using iterative theory-driven development to investigate how and why an instructional intervention works in authentic educational settings (Amiel \& Reeves, 2008; Anderson \& Shattuck, 2012).

Given the potential affordances of synchronous communication technology, we set forth to investigate "how" to successfully use live synchronous video-based communication (i.e., web conferencing) in predominantly asynchronous online courses. While we were not focused on how an instructional intervention can improve student outcomes in a specific authentic setting, we were interested in using a design-based research approach to create design knowledge (cf. Boling, 2010; Howard, Boling, Rowland, \& Smith, 2012) about how to use live synchronous web meetings in asynchronous online courses. Future research will need to be conducted to investigate how synchronous communication can be used to improve student outcomes.

Students in three different courses, each taught by the same instructor, took part in this study. Students were surveyed after the semester's final live meeting about their experiences and perceptions of attending live meetings. The survey was intentionally kept short, with students responding to a few Likert-style questions and three open-ended questions. The survey included questions like, "To what degree do you agree with the following statement, "Attending Happy Hours was a good use of my time" and "In your own words, why did you attend the Happy Hours?" The quantitative data from the survey was downloaded and descriptive statistics calculated for each question. The comments to the three open-ended questions were coded in NVivo 11 (QSR International, 2016). A descriptive coding process was used to catalog comments by topic and then group similar statements into main categories (Saldana, 2016).

Six students were then randomly selected from the pool of students who completed the survey to participate in follow-up semi-structured interviews as part of the first round of design experiments. During the interviews, participants were asked questions such as "What do you think of the live sessions? Do you like them? Do you find they are worth your time? How could live sessions be made more valuable to you?" The interviews were conducted by a graduate assistant. The interviews were recorded, transcribed, and then independently coded using an open-coding technique. Finally, end-of-course student evaluations were also used to triangulate the findings and further explore student perceptions of the instructor's use of live virtual office hours. The same surveys and end-of-course evaluations were then used to collect student feedback and perceptions after the second phase of design experiments.

\section{Office Hours Redesigned}

In the following section, we describe how the instructor iteratively redesigned his use of live, video-based, virtual office hours over a two-year period.

\section{1st Redesign}

The first thing the instructor did when he decided to start using live, video-based virtual office hours again was to rebrand his virtual office hours. Office hours implies something optional, something not important, something only for struggling students (Huang \& Hsiao, 2012). Research has shown that students usually do not attend office hours (in any format) and that when given the choice, they prefer to simply email questions directly to their instructor (Kitsantas \& Chow, 2007; Li, Finley, Pitts, \& Guo, 2011). This is in part because of flexibility but also the stress involved in asking questions, especially in front of other students (cf. Li et al., 2011). Inspired by his colleague, 
Krishna Pakala, the instructor renamed his virtual office hours as "Happy Hour." This was an attempt to portray virtual office hours as a more informal, social environment where students might feel more at ease to ask questions as they arise (and learn vicariously through others' questions and answers), commiserate with peers, and get to know each other better.

Office hours are traditionally offered each week. However, the instructor questioned whether this was needed in the courses he taught. Thus, rather than offering live virtual office hours each week, he strategically chose four key times throughout the semester to offer the four live virtual hours, each lasting 60 minutes. The first live session was offered three weeks into each course and the remaining three were scheduled three weeks apart. The hope was that this would be frequent enough to help students with major questions but not too frequent that it became a burden (for him or the students). He was fully aware though that four was not a magic number; between 3 to 6 meetings could be equally effective, depending on the course and context. Research, though, suggests that instructors should have more than two live synchronous sessions in order to have students feel comfortable with the technology (McBrien, Jones, \& Cheng, 2009).

Following suggestions in the literature (cf. Barclay, 2010), the live virtual office hours remained optional. However, the instructor chose to emphasize them more than he had emphasized office hours in the past. For instance, the date and times of each Happy Hour were set at the start of the semester and listed on the syllabus. The instructor had students living all over the United States as well as a number of students out of the country. Therefore, rather than trying to find a time that worked for all students, he opted for a time that worked for him and most of his students (many of which had full-time jobs) — which happened to be Wednesday evenings. He alternated times to enable students from both the east and west coast time zones to attend (e.g., the 1st and 3rd Happy Hour would be scheduled at 5:30pm and the 2nd and 4th happy hour would be scheduled at $6: 30 \mathrm{pm})$. He also posted information about each live session in the corresponding module of the learning management system. Then on the day of the live meeting, following Martin et al.'s (2012) recommendation, a reminder was posted in the course announcements. Finally, as suggested in the literature, the live meeting was recorded and the recording was posted online so those who could not attend were able to watch at their convenience (Barclay, 2012; Martin et al., 2012) as well as ask follow-up questions as needed.

\section{2nd Redesign}

The following year, the instructor made additional changes to his use of live, video-based virtual office hours based on feedback he received from students-which came from a survey, select interviews, and end-of-course evaluations (which will be discussed in more detail in the following section) — as well as his own experience offering live meetings (see Table 1 for a summary of these changes). First, based on student feedback, a Google Calendar invite was created for each meeting and students were invited to attend the meeting through the Google Calendar application (this university used the G Suite for Education core services). This provided students one more way to be reminded of the live virtual office hours. Second, based on student suggestions, he decided to allow students to earn points for attending the live meetings. While he could have added the points simply as extra credit, he decided instead to add the points as a part of the course participation points. Thus, this gave students the ability to choose whether they earn all their participation points for the course by taking part only in the asynchronous course discussions or earn some points by attending the live meetings. Thus, attendance was still optional but students could earn points for attending. Third, a mini instructional lesson was added to each Happy Hour session because students reported that they wanted some type of instruction if they were going to 
attend a live meeting; that is, the live meetings should not simply be a question-and-answer forum (like traditional office hours). Students also mentioned that there should be a way to ask questions that could be addressed during Happy Hour in case they were unable to attend; in response, when the instructor would post an announcement reminding students to attend a live meeting later that day, he asked students who could not attend to post any questions they had so that he could address them during the live meeting.

Based on this feedback, each future live meeting would start by addressing student questions; then there would be an instructional lesson, which was either a pre-planned lesson based on the content of the given module or a lesson based on students' past work (e.g., common errors the instructor noticed while grading student work).

\begin{tabular}{|c|c|c|}
\hline Initial Design & 1st Redesign & 2nd Redesign \\
\hline $\begin{array}{ll}\text { - } & \text { Live Virtual Office Hours } \\
\text { - } & \text { Weekly (Saturday mornings } \\
& \text { at } 10 \text { am) } \\
\text { - } & \text { Attendance was optional } \\
\text { - } & \text { Unstructured }\end{array}$ & $\begin{array}{ll}\text { - } & \text { Rebranded as "Happy } \\
\text { Hours" } \\
\text { - } \\
\text { Offered } 4 \text { times a semester } \\
\text { on Wednesdays (times } \\
\text { varied) } \\
\text { - } \begin{array}{l}\text { Dates \& times listed on } \\
\text { syllabus }\end{array} \\
\text { - } \quad \text { Remind students about } \\
\text { "Happy Hour" } \\
\text { - Attendance is optional } \\
\text { - Unstructured } \\
\text { - Recorded } \\
\text { - } \quad \text { Added Happy Hours within } \\
\text { corresponding modules }\end{array}$ & 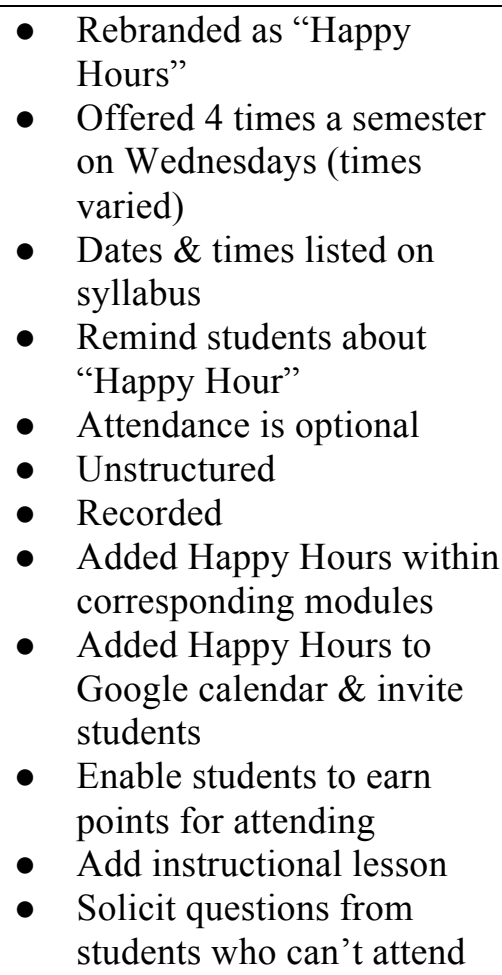 \\
\hline
\end{tabular}

Table 1. Design Changes of Live Virtual Office Hours

\section{Results}

As previously mentioned, our purpose was to find more effective ways to use live, videobased virtual meetings in predominantly asynchronous courses. More specifically, we wanted to find ways to improve student attendance, satisfaction, and overall perceptions of live, video-based virtual meetings. In the following section, we briefly describe the findings.

We were initially interested in getting more students to attend the optional live meetings and therefore make it feel like the live sessions were a good use of the instructor's and his students' time. While previously only about $10 \%$ of students attended one virtual office hour (i.e., 2 out of 
23 students), now about $50 \%$ of the students in each course are attending at least one Happy Hour semester after semester (i.e., 11-13 out of 23 students) and about 25\% (i.e., 6-7 out of 23 students) attend every Happy Hour in a given semester (Table 2). Thus, while every student is not able to, or chooses not to, attend a live session, the design changes appear to be associated with an overall increase in attendance. Further, the analytics of the archived recordings of the live meetings (which are uploaded as unlisted videos on YouTube the following week of each live session) revealed that each recoded live session has an average of 8 "views," thus in ways increasing "attendance" even more through post-session review by students not in live attendance.

\begin{tabular}{lcccc}
\hline Course & Enrollment & $\begin{array}{c}\text { \# of Students } \\
\text { Attending a Happy } \\
\text { Hour }\end{array}$ & $\begin{array}{c}\text { Average } \\
\text { Attendance }\end{array}$ & \#Attending All \\
\hline Internet for Educators & 74 & $41(55 \%)$ & 2.56 & $9(22 \%)$ \\
Online Course Design & 35 & $18(51 \%)$ & 1.94 & $5(28 \%)$ \\
$\begin{array}{l}\text { Doctoral Studies } \\
\text { Orientation }\end{array}$ & 16 & $9(56 \%)$ & 3.11 & $3(33 \%)$ \\
\hline
\end{tabular}

Table 2. Happy Hour Attendance

We were also interested in why students attended the live meetings and whether they enjoyed them (Table 3). Students reported that they attended the live meetings to learn the course material $(M=3.88$ on a 5-point scale), learn course requirements $(M=3.76)$, and to get questions answered $(M=3.85)$. But the number one reason students said they attended the live sessions was to get to know their instructor better (i.e., the instructor's social presence; $M=4.38$ ). Finally, students reported that attending the live sessions was a good use of their time $(M=4.43)$. Further, a few students, each semester, would mention the live sessions (i.e., Happy Hour) when asked in the end-of-course evaluations, "Which aspects of this course were most valuable to your overall learning experience?" The following are a few examples of what some students said in the instructor's end-of-course student evaluations:

- "I loved the happy hours and the video feedback he would give"

- "The instructional videos and forum feedback as well as the Happy hour connection were all important to making course more than just a long tutorial."

- “...videos, happy hours and personal tutoring made this course the only online course I have ever had where I really felt a connection to the professor personally and to the other students."

- "I enjoyed the "Happy Hours" as this helped me feel more connected to my peers and the instructor."

- "The "happy hour" online webchats were also very useful and fostered a sense of community in the class."

- "...enjoyed the happy hours as a way to connect with other learners in the cohort. Appreciated the informal approach to it to ease new students and alleviate their fears of belonging." 
- "I appreciated the Happy Hour... question/answer sessions, casual and frank preparation for the doctorate program, and general support and cheerleading."

\begin{tabular}{|c|c|c|c|c|c|c|c|}
\hline \multirow{2}{*}{$\begin{array}{l}\text { To what degree do you agree with this } \\
\text { statement, } \\
\text { I attended Happy Hours to learn course } \\
\text { material / content }\end{array}$} & \multicolumn{5}{|c|}{ [Strongly Disagree------Strongly Agree] } & \multirow{2}{*}{$\begin{array}{c}\mathbf{M} \\
3.88\end{array}$} & \multirow{2}{*}{$\begin{array}{l}\text { SD } \\
1.11\end{array}$} \\
\hline & 2 & 6 & 15 & 19 & 25 & & \\
\hline $\begin{array}{l}\text { I attended Happy Hours to learn more } \\
\text { about course requirements }\end{array}$ & 3 & 10 & 11 & 20 & 24 & 3.76 & 1.21 \\
\hline $\begin{array}{l}\text { I attended Happy Hours to get my } \\
\text { questions answered }\end{array}$ & 3 & 6 & 17 & 14 & 28 & 3.85 & 1.19 \\
\hline $\begin{array}{l}\text { I attended Happy Hours to get to know } \\
\text { my instructor better }\end{array}$ & 1 & 1 & 7 & 21 & 38 & 4.38 & .85 \\
\hline $\begin{array}{l}\text { I attended Happy Hours to get to know } \\
\text { my fellow students better }\end{array}$ & 2 & 5 & 15 & 19 & 27 & 3.94 & 1.09 \\
\hline $\begin{array}{l}\text { Attending Happy Hours was a good use } \\
\text { of my time }\end{array}$ & 0 & 2 & 3 & 27 & 36 & 4.43 & 0.72 \\
\hline
\end{tabular}

Table 3. Student Perceptions of Happy Hours (i.e., Synchronous Live Meetings)

We also wanted to learn more about why students attended and how the use of live virtual office hours could be improved through each iteration. Via the survey, we asked students the following open-ended questions:

Q1: In your own words, why did you attend the Happy Hours?

Q2: What would you change about Happy Hours if you could?

Q3: Final comments.

The main categories of coded comments are listed in Table 4 along with a percentage breakdown of comments coded under each category. Many of the categories span across multiple questions due to similarities in responses. For example, participants discussed Personal Interaction topics in response to all three questions (Q1, Q2, Q3). In Table 4, each category is described and then is followed by a summary of where coded comments appeared in response to the three open-ended questions. 
Personal Interaction: These comments emphasize interaction with instructor and/or peers in the live setting.

Satisfied or Appreciative: These comments referred to satisfaction with aspects of the live sessions or general appreciation for the availability of live sessions.

Useful Information: Comments regarding the value or usefulness of the live sessions.

Timing: Comments pertaining to the timing of the live sessions and schedule conflicts.

Incentives: Comments related to incentives such as points given for attending.

Technology: Comments about the technologies used for the live session.

Advanced Preparation: These comments emphasize student requests for discussion topics prior to the live session.

Content and Focus: These comments are on how focused and on track (or not) the sessions were:

\begin{tabular}{|c|c|c|l|l|}
\hline Q1 & Q2 & Q3 & Main Categories for Coded Comments & $\begin{array}{l}\text { Percentage of Coded } \\
\text { Comments* }\end{array}$ \\
\hline $\mathrm{x}$ & $\mathrm{x}$ & $\mathrm{x}$ & Personal Interaction & 26 \\
\hline $\mathrm{x}$ & $\mathrm{x}$ & $\mathrm{x}$ & Satisfied or Appreciative & 24 \\
\hline $\mathrm{x}$ & & & Useful Information & 15 \\
\hline $\mathrm{x}$ & $\mathrm{x}$ & $\mathrm{x}$ & Timing & 14 \\
\hline $\mathrm{x}$ & $\mathrm{x}$ & $\mathrm{x}$ & Incentives & 8 \\
\hline $\mathrm{x}$ & $\mathrm{x}$ & $\mathrm{x}$ & Technology & 5 \\
\hline & $\mathrm{x}$ & $\mathrm{x}$ & Advanced Preparation & 5 \\
\hline
\end{tabular}

* Note. There was a total of 252 coded statements. Percentages of coded comments were rounded to the nearest whole number, which accounts for the total at slightly less than 100 .

Table 4. Coding by Question and Category

Below is a sample of student responses within each of the eight coding categories:

Personal Interaction: Comments about interaction with instructor and/or peers in the live setting.

- "It was a great way to connect with the instructor and other students. There's a difference between being a participant 'live' and just listening to the recording."

- "Since we are in an online course, I liked the opportunity to see my instructor and classmates 'live.' This is why I attended the first Happy Hour." 
- "I attended the Happy Hour sessions for two reasons. First, it's difficult to connect with people in an online program, it was nice to be able to see people and hear their voices in real-time for a change."

Satisfied or Appreciative: Comments about satisfaction with aspects of the live sessions or general appreciation for the availability of live sessions.

- "I was satisfied with the Happy Hours opportunity in terms of its content and structure. It was casual and not formalized so that it was a comfortable environment for people who have not met each other."

- "I appreciate that Patrick took time to hold the Happy Hour conferences. It was very helpful to be able to ask questions and it was great to get to know some of my classmates."

- "I really enjoyed attending Happy Hours. I think this is a great idea to get answers and see where everyone else is in the course. All courses should have Happy Hours."

Useful Information: Comments about the value or usefulness of the live sessions.

- "To gain additional insights in the assignments and activities. It was very helpful to hear Patrick's viewpoints on finer issues. Also, I always learn from what other people are doing/know."

- "I wanted to be kept in the loop and receive any additional information the instructor thought was helpful for the course."

- "I attended to make sure that I was on task with my assignments. I also needed clarification on coding and web design when the course began. The happy hour sessions were extremely valuable to me when I started the course."

Timing: Comments about the timing of the live sessions and schedule conflicts.

- "I was only able to attend the first one because they were all on Wednesdays and that is the day that my school has after school meetings. By the time I got out and home to log in, the Happy Hour was over."

- "I would change up the day of the week and or the time of the day that they are scheduled. That way more people could attend all of them."

- "As an east coast student with a toddler child at home, having the session at 7-8pm EST was very difficult for getting my child ready for bed-I would be happy to have it later for my own personal schedule."

Incentives: Comments about incentives such as points given for attending.

- "The reason I said that I wouldn't attend without the points was because I wouldn't have gone to start without the points. Knowing what I know now, I feel they were worth going with or without credit, but I wouldn't have gone to the first one to find that out without the tempting participation points."

- "I wish there was another way to make up the missed participant points for those who can't attend happy hours live. I know the points probably don't mean that much in the overall picture but I feel like I've failed for something out of my control.” 
- "If points weren't given for attending, I might not have attended at first or as regularly and I would've missed out. The points motivated me to go to the first one and then I looked forward to the next ones."

Technology: Comments about the technologies used for the live session.

- "I teach online, so I was curious about seeing another platform other than Blackboard and thought it would be good to have a live experience with this class since I hadn't done that with any others during the program."

- "I want to check it out as this was my first time in an online course. I also wanted to try the online meeting technology which I have never used before."

- "This was my first time participating in a web conference at Boise State. I was nervous about having to be seen on camera which fortunately did not happen. I would like to use a similar software to have teachers engage with independent studies that can't attend school every day. I wish adobe connect software wasn't so expensive."

Advanced Preparation: Comments about student requests for discussion topics prior to the live session.

- "It might be helpful to have students submit questions prior to the happy hour so that you could tailor the hour to those attending. It would be nice if there was a way to encourage students to come up with questions before happy hour so there were more questions being asked.

- It would be good to have participants ask about their primary concerns/ questions on a form (such as this) before everyone attended."

Content and Focus: Comments about how focused and on track (or not) the sessions were:

- "I think the Happy Hours got sidetracked by questions about comps and dissertations. All of which are years away. I wish they were more focused on the course. Maybe dedicate one late in the course for folks that had questions."

- "I feel like we threw a lot of random questions at you during $\mathrm{HH}$, which made it difficult for there to really be a flowing discussion. I'm sure this was partially because we are all new the program and there are simply a lot of questions that we have about coursework, formats, etc."

Students comments were invaluable as they helped clarify survey results and provided specific insight into how to better design virtual office hours in online courses.

\section{Discussion}

Most online courses today rely predominantly on asynchronous, text-based communication. This is not surprising when one considers the independent, correspondence- study tradition of distance learning from which online learning evolved. While we understand the benefits of asynchronous, text-based online communication, we also believe-based on the literature (Fadde \& Vu, 2014; Finkelstein, 2006; Huang \& Hsiao, 2012; Martin \& Parker, 2014; $\mathrm{Ng}$, 2007; Power, 2008) and our experiences - that there are inherent affordances of communicating in real time, "face-to-face," using synchronous video communication technology. 
However, over the years we have struggled to effectively use live, video-based synchronous communication in our online courses.

In this study, we set out to investigate how to use live, video-based synchronous technology during office hours in three different predominantly asynchronous online graduate courses. Whether online or face-to-face, most students do not attend office hours. Thus, our first goal was to get students to attend office hours in the first place. While we were aware that simply requiring students to attend would likely increase attendance, we wanted to keep office hours as an optional activity. Over the two-year period, we found that as we emphasized the importance of the live virtual office hours more, reminded students of when the meetings were (i.e., by listing it as an activity in the course, sending calendar invitations, and reminders the day of the meetings), added an instructional component, and enabled students to earn points for attendance, overall attendance increased. While some students chose not to attend, more than half of each class attended or watched the archived recording of the meeting. Additional research, though, is needed to see if similar strategies could increase attendance in other subject areas.

In addition to increasing the overall attendance of office hours, we also wanted students to feel like attending was a good use of their time and to better understand what they liked or did not like about attending live, video-based office hours. The results suggest that students who attended the live, video-based office hours liked them, found them helpful, and even wished that other instructors used them in their courses. However, students also reported that they sometimes struggled getting the technology to work and sometimes could not attend the live meetings due of prior commitments. Additional research is needed to better understand why some students never attended a live meeting as well as the relationship between participation in live meetings, student retention, and student learning.

\section{Design Recommendations}

Incorporating synchronous learning opportunities and events into online courses is an important design decision. We do not believe that synchronous live meetings are appropriate for all courses, all instructors, or all students. But we do believe that they can add value to predominantly asynchronous online courses, when used intentionally, with thought and care. This study illuminates several design recommendations derived from the analysis of the collected data-some of which align with previous work (e.g., Barclay, 2010 and Martin et al., 2012), but many that do not.

Based on our experience, the following recommendations are offered to support the effective use of live office hours:

\section{Orientation to live sessions}

1. Refer to virtual office hours using a more inviting title. For example, for more informal live sessions, select a name like Happy Hours, Coffee Breaks, Afternoon Tea, Bat Cave, and Around the Campfire. For more formal live sessions, consider titles such as Consultations, Design Studio, Conference Room, Headquarters, and Open Space.

2. Inform students at the start of the semester when synchronous sessions are scheduled.

3. Inform students of the agenda for each live session in advance.

4. Remind students of approaching live sessions in daily/weekly communications, such as via the announcements feature of a learning management system. 
5. Provide low-stakes opportunities for students to troubleshoot and get acquainted with the synchronous format and associated tools. For example, during the first few weeks of a course, have each student — or small groups of students - visit with you in Adobe Connect for the sole purpose of checking out tool functionality, and to hear and see each other laugh.

6. Share a short recording of a live session with students new to live sessions so they can get a sense of how they work and what to expect in advance of participating in a live session.

\section{Scheduling}

7. Consider students' time zones when scheduling live sessions. Use a tool like Doodle, for example, to determine best times to meet.

8. Schedule live sessions strategically; they do not need to be scheduled weekly. For example, schedule live sessions prior to the due dates of major deliverables or in advance of exams.

9. Vary the day of the week and time of day. Consider scheduling two live sessions per week on different days and at different times of day.

\section{Relevance}

10. Be transparent with students as to your reasons for including live sessions in your online courses.

11. Ask students to share questions in advance of live sessions so sessions may be tailored to meet specific goals, needs, and interests.

12. Make live sessions relevant in terms of content and activity. Make sure the live sessions add value to the students' learning experience in an online course. For example, include a brief direct-instruction component, demonstration, or guest speaker in each live session.

13. Provide a comparable learning experience for those unable to attend a live session. For example, give those students specific questions/prompts to respond to while watching the recording.

\section{Incentives and assessment}

14. Add incentives for attendance (e.g., require it or allow students to earn points), but provide options-equitable in terms of learning experience-for those who have schedule conflicts.

15. Involve students in learning activities during synchronous sessions that support their work on projects, papers, and so on. For example, provide a lab demonstration that will help students complete their own experiments in the lab.

\section{Interaction}

16. Start each live session with a brief ice-breaker and/or get-to-know-you activity to help establish connections between and among instructor and students, and to get warmed up with the technology before launching into more coursework-oriented activities.

17. Provide both informal and structured time and opportunity for students to interact with each other.

18. Have students contribute to or determine "rules of engagement" for interacting with each other during live sessions. 
19. Model the type and level of interaction that supports student engagement during live sessions.

20. Get students involved in the live meetings. For example, have them collaborate on a response to a problem of practice or peer review each other's work.

21. Ask for questions from students who are unable to attend, and respond to the questions during the live session.

\section{Conclusions}

Prior to this research study, the instructor and co-authors were dissatisfied with the reach and effectiveness of virtual office hours in their online courses. They knew there was great potential value even if only for the few students who did participate in virtual office hours, however they consistently questioned whether or not the time spent planning, promoting, and facilitating live sessions was a good use of a finite resource - their time and energy. They were curious about considerations like: Do live, video-based, virtual office hours have to be offered each week? Do they have to be offered at the same time each week? Should students be required to attend virtual office hours? This study helped them think through their instructional decisions and associated instructional strategies and develop a set of design recommendations to guide their practice and the practice of others.

As synchronous video-based communication technologies continue to improve and become more reliable and easy to use, instructors are likely to take advantage of the instructional potential of live sessions. Ideally, online courses would include both asynchronous and synchronous learning opportunities based on the instructional goals of the course, taking advantage of the affordances of both formats. In fact, on-campus courses may learn associated best practices from online courses; the "flipped classroom" approach is an example of how on-campus courses can be structured to best take advantage of synchronous learning opportunities (i.e., those occurring in a classroom, lab, or the like) and asynchronous learning opportunities (i.e., homework). Using a design-based research approach to create new knowledge about how to use live synchronous web meetings in asynchronous online courses, we have identified a set of design recommendations that match instructional goals and strategies based on currently available synchronous tools and technologies. These design recommendations inform our online and oncampus teaching practices, and have provided us with an ongoing line of inquiry to pursue as we explore additional ways in which synchronous video-based web tools and technologies may be used to support student learning. 


\section{References}

Ambrose, S. A., Bridges, M. W., DiPietro, M., Lovett, M. C., \& Norman, M. K. (2010). How learning works. San Francisco, CA: Jossey Bass.

Amiel, T., \& Reeves, T. C. (2008). Design-based research and educational technology: Rethinking technology and the research agenda. Educational Technology \& Society, 11 (4), 29-40.

Anderson, T. (2003). Getting the mix right again: An updated and theoretical rationale for interaction. The International Review of Research in Open and Distributed Learning, 4(2). Retrieved from http://www.irrodl.org/index.php/irrodl/article/view/149/230

Anderson, T., \& Shattuck, J. (2012). Design-based research: A decade of progress in education research? Educational Researcher, 41(1), 16-25.

Astin, A. W. (1993). What matters in college? Four critical years revisited. San Francisco, CA: Jossey Bass.

Barclay, K. (2010). Humanizing learning-at-distance: Best practice guidelines for synchronous instructors. In Web-Based Education: Concepts, Methodologies, Tools and Applications (pp. 1232-1238). Hershey, PA: IGI Global.

Bernard, R. M., Abrami, P. C., Borokhovski, E., Wade, C. A., Tamim, R. M., Surkes, M. A., \& Bethel, E. C. (2009). A meta-analysis of three types of interaction treatments in distance education. Review of Educational research, 79(3), 1243-1289.

Boettcher, J. V., \& Conrad, R. M. (2016). The online teaching survival guide: Simple and practical pedagogical tips (2nd ed.). San Francisco, CA: Jossey-Bass.

Boling, E. (2010). The need for design cases: Disseminating design knowledge. International Journal of Designs for Learning, 1(1), 1-8.

Bolliger, D. U., \& Inan, F. A. (2012). Development and validation of the online student connectedness survey (OSCS). The International Review of Research in Open and Distributed Learning, 13(3), 41-65. Retrieved from http://www.irrodl.org/index.php/irrodl/article/view/1171/2206

Borup, J., West, R. E., \& Graham, C. R. (2012). Improving online social presence through asynchronous video. Internet and Higher Education, 15(3), 195-203.

Bowman, L. (2010). Online learning: A user-friendly approach for high school and college students. Lanham, MD: Rowman \& Littlefield Education.

Brown, A. L. (1992). Design experiments: Theoretical and methodological challenges in creating complex interventions. Journal of the Learning Sciences, 2, 141-178.

Clark, R. E. (1983). Reconsidering research on learning from media. Review of educational research, 53(4), 445-459.

Clark, R. E. (1994). Media will never influence learning. Educational technology research and development, 42(2), 21-29. 
Collins, A. (1992). Toward a design science of education. In New directions in educational technology (pp. 15-22). Springer, Berlin, Heidelberg.

Cuban, L. (2009). Oversold and underused. Harvard University Press.

Chickering, A., \& Gamson, Z. (1987, March). Seven principles for good practice in undergraduate education. AAHE Bulletin, 3-7.

Dunlap, J. (2005). Workload reduction in online courses: Getting some shuteye. Performance Improvement, 44(5), 18-25.

Dunlap, J., Bose, D., Lowenthal, P. R., York, C. S., Atkinson, M., \& Murtagh, J. (2016). What sunshine is to flowers: A literature review on the use of emoticons to support online learning. In S. Y. Tettegah \& M. Gartmeier (Eds.), Emotions, design, learning and technology (pp. 163-182). San Diego, CA: Elsevier.

Fadde, P. J., \& Vu, P. (2014). Blended online learning: Benefits, challenges, and misconceptions. In P. R. Lowenthal, C. S. York, \& J. C. Richardson (Eds.), Online learning: Common misconceptions, benefits, and challenges (pp. 38-48). Hauppauge, YU. Nova Publishers.

Finkelstein, J. E. (2006). Learning in real time: Synchronous teaching and learning online. San Francisco, CA: Jossey-Bass.

Gunawardena, C. N. (1995). Social presence theory and implications for interaction and collaborative learning in computer conferences. International Journal of Educational Telecommunications, 1(2/3), 147-166.

Gunawardena, C. N., \& Zittle, F.J. (1997). Social presence as a predictor of satisfaction within a computer-mediated conferencing environment. American Journal of Distance Education, 11(3), 8-26.

Howard, C. D., Boling, E., Rowland, G., \& Smith, K. M. (2012). Instructional design cases and why we need them. Educational Technology, 52(3), 34-39.

Hrastinski, S., Keller, C., \& Carlsson, S. A. (2010). Design exemplars for synchronous elearning: A design theory approach. Computers \& Education, 55(2), 652-662.

Hsiao, E. L. (2012). Synchronous and asynchronous communication in an online environment: Faculty experiences and perceptions. Quarterly Review of Distance Education, 13(1), 1530 .

Ice, P., Curtis, R., Phillips, P., \& Wells, J. (2007). Using asynchronous audio feedback to enhance teaching presence and students' sense of community. Journal of Asynchronous Learning Networks, 11(2), 3-25.

Kitsantas, A., \& Chow, A. (2007). College students' perceived threat and preference for seeking help in traditional, distributed, and distance learning environments. Computers \& Education, 48(3), 383-395.

Ko, S., \& Rossen, S. (2017). Teaching online: A practical guide (4th ed.). New York, NY: Taylor \& Francis. 
Li, L., Finley, J., Pitts, J., \& Guo, R. (2011). Which is a better choice for student-faculty interaction: synchronous or asynchronous communication? Journal of Technology Research, 2, 1-12.

Lowenthal, P. R. (2010). The evolution and influence of social presence theory on online learning. In T. T. Kidd (Ed.), Online education and adult learning: New frontiers for teaching practices (pp. 124-139). Hershey, PA: IGI Global.

Ludwig-Hardman, S., \& Dunlap, J. C. (2003). Learner support services for online students: scaffolding for success. The International Review of Research in Open and Distributed Learning, 4(1).

Martin, F., \& Parker, M. A. (2014). Use of synchronous virtual classrooms: Why, who, and how? Journal of Online Learning and Teaching, 10(2), 192-210.

Martin, F., Parker, M. A., \& Deale, D. F. (2012). Examining interactivity in synchronous virtual classrooms. The International Review of Research in Open and Distributed Learning, 13(3), 228-261. Retrieved from http://www.irrodl.org/index.php/irrodl/article/view/1174/2253

McBrien, J. L., Cheng, R., \& Jones, P. (2009). Virtual spaces: Employing a synchronous online classroom to facilitate student engagement in online learning. The International Review of Research in Open and Distributed Learning, 10(3). Retrieved from http://www.irrodl.org/index.php/irrodl/article/view/605/1264

Moore, J. L., Dickson-Deane, C., \& Galyen, K. (2011). E-Learning, online learning, and distance learning environments: Are they the same? Internet and Higher Education, 14(2), 129135.

Murphy, E., Rodríguez-Manzanares, M. A., \& Barbour, M. (2011). Asynchronous and synchronous online teaching: Perspectives of Canadian high school distance education teachers. British Journal of Educational Technology, 42(4), 583-591.

Ng, K. C. (2007). Replacing face-to-face tutorials by synchronous online technologies: Challenges and pedagogical implications. The International Review of Research in Open and Distributed Learning, 8(1). Retrieved from http://www.irrodl.org/index.php/irrodl/article/view/335/764

Oppenheimer, T. (1997). The computer delusion. The Atlantic Monthly, 280(1), 45-62.

Palloff, R. M., \& Pratt, K. (2007). Building online learning communities: Effective strategies for the virtual classroom (2nd ed.). San Francisco, CA: Jossey-Bass.

Power, M. (2008). The emergence of a blended online learning environment. Journal of Online Learning and Teaching, 4(4), 503-514.

Reeves, T. C., Herrington, J., \& Oliver, R. (2005). Design research: A socially responsible approach to instructional technology research in higher education. Journal of Computing in Higher Education, 16(2), 96-115. 
Richardson, J. C., \& Lowenthal, P. (2017). Instructor social presence: Learners' needs and a neglected component of the community of inquiry framework. In A. Whiteside, A. Garrett Dikkers, \& K. Swan, (Eds), Social presence in online learning: Multiple perspectives on practice and research (pp. 86-98). Sterling, VA: Stylus.

Saldana, J. (2016). The coding manual for qualitative researchers (3rd ed.). Thousand Oaks, CA: Sage.

Shea, P., \& Bidjerano, T. (2009). Community of Inquiry as a theoretical framework to foster "epistemic engagement" and "cognitive presence" in online education. Computers \& Education, 52(3), 543-553.

QSR International. (2016). NVivo 11 for Windows [Computer software]. Retrieved from http://www.qsrinternational.com/product/nvivo11-for-windows 